\title{
A Group Intervention or Smoking Cessation: The Impact of a Group Cohesion Strategy on Attendance and Outcome
}

\author{
Renata Pires-Yfantouda ", Catherine Sykes \\ Department of Psychology, City University, London, EC1V 0HB, UK
}

\begin{abstract}
This study investigated the effectiveness of incorporating methods to boost group processes as means of enhancing attendance and abstinence from smoking for 4 consecutive weeks following a set quit day (self-report and $\mathrm{CO}$ monitored on expired breath). A total of 140 smokers (age: $\mathrm{M}=48, \mathrm{SD}=12.45 ; 47 \%$ male, $53 \%$ female) attended the North West London Specialist clinic. Abstinence was verified by CO levels in expired breath and self-reports. Participants were allocated to two conditions; half attended the traditional Hajek group intervention (HGI) and the remaining received (HGI) plus a "breaking the ice exercise" (BIE). HGI Findings indicated the groups with emphasis on social support and where initial rapport was built were significantly more successful. This study suggests that group methods, rapport and social support play a role in group dynamics affecting therapeutic outcome. Incorporating a simple intervention where patients address each other's motives for joining the Clinic and introduce their peers augments cohesiveness.
\end{abstract}

Keywords Addiction; Smoking, Social Support, Behavior, Nursing Practice, Psychology

\section{Introduction}

Cigarette smoking is one the greatest avoidable causes of premature death and disability, with around 81,400 smokers dying from smoking-related causes every year in England alone (The National Health Service (NHS) Information Centre, 2010).

Currently, there are 13 million smokers in the United Kingdom (UK). Smoking is responsible for an estimated 364,000 hospital admissions and $£ 1.5$ billion a year in health service costs (National Institute of Clinical Excellence (NICE), 2002; Edwards, 2004.) Taking into account that approximately $70 \%$ of smokers in the UK want to quit and the fact that the health and possible psychological benefits of quitting are substantial, meeting the challenge of helping smokers to become long-term quitters has enormous public health implications.

The probability of success for behavioral smoking cessation programs varies according to the type of intervention (Viswesvaran \& Schimidt, 1992). According to Stead and Lancaster (2002), smoking cessation interventions normally include methods designed to help smokers to cope during their abstinence, social skills training, contingency management, self-control and cognitive behavioral

* Corresponding author:

r.pires@city.ac.uk (Renata Pires-Yfantouda)

Published online at http://journal.sapub.org/ijpbs

Copyright (C) 2012 Scientific \& Academic Publishing. All Rights Reserved interventions.

Specialist Smoking Cessation Services (SCS) were first established in the UK in Health Action Zones in England in 1999/2000. The evidence base for these services was set out in smoking cessation guidelines published in the journal Thorax (Raw, McNeill, \& West, 1998), and recommended that "intensive smoking cessation support should where possible be conducted in groups, include coping skills training and social support, and should offer around five sessions of about one hour over one month, and follow-up". Smoking cessation group support became the treatment of choice in the NHS, as it was considered to be "much more cost-effective" (Raw et al., 1998). The abstinence-oriented approach adopted by the NHS was developed by the Maudsley Clinic (Hajek, 1989). The purpose of this approach is to analyze the motives behind group members' behavior, to provide opportunities to engage in social learning, to generate emotional experiences and to transfer information and teach new skills (Hajek, 1996, 1985). The abstinence-oriented approach sees the discomfort of withdrawal as remediable. Smokers' self-efficacy is built up before a "quit date" is set, and they are empowered and helped to achieve their objective of quitting smoking during the initial stage of their withdrawal from nicotine.

It has been suggested that the UK offers the most comprehensive, easily accessible and inexpensive (free through the NHS) smoking cessation interventions in the world (Raw et al., 2009). However, despite the fact that the abstinence-oriented approach adopted by the NHS has 
proven to be effective in the short term and is recommended by NICE $(2002,2008)$, it is not achieving medium and long-term outcomes. Studies have found that $75 \%$ of smokers who achieve four weeks of abstinence relapse within the first year (Ferguson, Bauld, Chesterman, \& Judge, 2005) and that a further 30\% relapse after that (Etter $\&$ Stapleton, 2006). The evidence supporting this approach, which was presented in a systematic review (Law \& Tang, 1995), was also criticized by a systematic review conducted later by Pires-Yfantouda (2010). Despite the fact that this intervention recommends the inclusion of elements designed to enhance social support, it does not specify the format that they should take. More recent research has focused on identifying the components of interventions that might play a role in sustaining abstinence from smoking (Taylor, Miller, \& Herman et al., 1996; Marks \& Sykes, 2001; Simon, Solkowitz, \& Carmody et al., 1997; Feeney, McPherson, \& Connnor, 2001).

Extensive research was conducted concerning the impact of methods designed to increase group cohesiveness and social support in smoking cessation group interventions. Some studies have evaluated the impact of processes which aim to increase group support such as having a "buddy" or a "quit mate" (West, Edwards, \& Hajek, 1998), whereby smokers attending group support are given the task of finding someone within the group to whom they can talk about their process of abstinence between sessions. In a review of buddy systems in smoking cessation programs (May \& West, 2000), the authors concluded that the research methodology employed in many of the studies was rather poor. They also suggested that in the context of a smokers' clinic, the use of buddies may be of some benefit, despite the fact that there is a lack of evidence regarding the efficacy of the use of buddies in community interventions. Previous audits in a North West London Borough (2003, 2004 \& 2005) indicated that many group members were reluctant to contact their "quit-mates", because they feared being judged. These audits also indicated that people who contacted their quit-mates were more likely to still be quitters at the end of the program. It is likely that smokers attending group support would feel more relaxed around other group members if group support strategies were incorporated during the early stages of the intervention.

Predominantly, the research has pointed towards the important role in terms of attendance and cessation rates played by social support. Kviz, Crittenden, Madura and Warnecke (1994) evaluated the effectiveness of social support in a minimal contact self-help smoking cessation program. This study suggested that buddy support is helpful in remaining abstinent from smoking and suggested that it should be used in minimal-contact smoking cessation programs.

In a similar study, also conducted on a minimal-contact smoking cessation program, $25 \%$ of participants had a buddy and it was found that those with a buddy were twice as likely to quit as participants without a buddy (Kviz et al., 1994). However, a more recent randomized controlled trial of a social support ("buddy") intervention for smoking cessation found that smokers in the buddy condition were no more likely than smokers in the control condition to still be abstinent at one, four or 26 weeks (May, West, Hajek, McEwen, \& McRobbie, 2006). After controlling for potential confounders, the difference was not significant (odds ratio $=1.45(95 \% \mathrm{CI} ; 0.92-2.29), \mathrm{p}=0.06)$. The authors were unable to demonstrate that a buddy system improved abstinence rates within group treatment programs.

Fisher (1997) suggested that social support serves as an alternative to smoking only if it is provided continuously. Fisher stressed that "although social support has been repeatedly correlated with abstinence, social support intervention for smoking cessation has not been markedly successful". In a study conducted by Mermelstein et al. (1986), it was found that the longest effect that social support had in terms of abstinence from smoking was three months, as it did not have any significant effect in the 12-month follow-up. Furthermore it seems that the smoking habits of family and friends might be better predictors of the long-term support they will provide (Fisher, 1997).

Valois et al. (1996) found a correlation between high levels of social support and low levels of depression while quitting smoking. Furthermore, they found that people with lower levels of depression were more likely to quit smoking. This could be an indication that a link between social support and smoking abstinence might still exist. Furthermore, Digusto and Bird (1995) found that people who had social support were more likely to remain abstinent after one week than those with lower levels of social support.

Despite the fact that studies looking at the impact of social support in smoking cessation interventions can be very different in terms of their methodology, most have shown social support to be significant (Hajek, 1996). The key reasons for offering interventions in a group context are to create opportunities to engage in social learning, to generate emotional experiences and to transfer information and teach new skills (Hajek, 1996, 1985).

Some studies have evaluated the impact of group support on abstinence from smoking using a range of methods. Nevertheless, no studies have evaluated the impact of specific components of interventions on group cohesiveness, such as exercises designed to "break the ice". The value of engaging group members and boosting group cohesiveness has been recognized by various entities engaged in smoking cessation in many countries, including the United States of America (USA), and these aspects have become a blueprint for good clinical practice. According to Orleans, Arkin and Backinger (2003), building successful relationships and social support among members of smoking cessation groups is crucial if they are to achieve similar goals. These researchers suggest that smoking cessation group support should incorporate group activities designed to bring participants together as a coordinated entity, thereby fostering communication between and among members. According to Thorax (1998), "where groups are used, there is some evidence to suggest that they should be 'group 
orientated' rather than 'therapist orientated', aiming to foster group cohesion". They also recommend that health professionals who co-facilitate group interventions should focus on building rapport between group members in order to increase group cohesiveness.

It is likely that group activities designed to "break the ice" would increase group cohesiveness, as they would help group members to feel supported by each other. Such strategies are simple, easy to implement and may be particularly useful in interventions in which members are encouraged to find quit-mates within their smoking cessation group so that they can share their difficulties outside the group therapy sessions, as stated in Hajek's method (1989).

The purpose of this study is to determine the impact of incorporating a breaking the ice exercise (BIE) into the Hajek's Group Intervention (HGI), compared to a control group using the HGI without the BIE.

\section{Methods}

\subsection{Design and Sample}

Data for this study was collected using a cross-sectional design. A comparison of two groups (HGI +BIE and HGI) was carried out. The BIE was incorporated during the first therapeutic session in order to boost group processes and to increase social; interaction and support as a means of enhancing attendance and abstinence from smoking for four consecutive weeks following a set quit date.

A total of 140 smokers (age: $\mathrm{M}=48, \mathrm{SD}=12.45 ; 47 \%$ male, $53 \%$ female) who attended the HGI clinic $(\mathrm{N}=70)$ or the HGI with BIE $(\mathrm{N}=70)$ took part in this study. The groups were created so that they matched in terms of socio-demographic characteristics.

The majority of the participants in the HGI (68\%) and the HGI + BIE $(66 \%)$ groups were married or living with a partner. A high proportion of their partners also smoked in the HGI $(42 \%)$ and HGI + BIE (39\%) groups.

The majority of smokers were referred to our service through their General Practitioners (GPs) 74\%).

Smokers who opted for group support were sent an invitation pack with a stamped self-addressed envelope. The invitation pack contained leaflets and booklets with information about smoking, health and medication (NRT/Zyban/Champix) and information about the abstinence-oriented approach (Hajek, 1991) and the BIE exercise. In order to join one of the group support sessions, the participants had to fill in their details and post the form back. The intervention program was held in a specialist smokers' clinic and was based on the withdrawal-oriented therapeutic approach for smokers (Hajek, 1989). Consent was obtained from participants to take part in this study. This study followed appropriate ethical procedures according to the British Psychological Society Code of Ethics and Conduct (2009).

\subsection{Measures}

The dependant variables were four weeks of abstinence, measured via $\mathrm{CO}$ levels and session attendance. The independent variable was the group format.

Abstinence was defined as continuous abstinence over four weeks, and was verified by $\mathrm{CO}$ levels in expired breath and self-reports.

\subsection{Procedure}

Each participant was allocated to one of two conditions; half attended the traditional HGI and the other half attended the HGI with the addition of a BIE. The same co-facilitators (a nurse and a health psychologist) ran all of the sessions.

HGI (Hajek, 1989) comprises a clinic run by specialist smoking cessation advisors offering behavioral and pharmaceutical support to aid smoking cessation. Pharmacological support includes nicotine replacement therapy (NRT), bupropion (Zyban), or varenicline (Champix), which are licensed on the NHS, with NRT also available from pharmacies without a prescription. According to Hajek (1989), five weekly evening sessions should be offered over four weeks after the quit date:

The first session is introductory with participants expected to stop after the second session. NRT is distributed and discussed at the first session. From the second session, meetings focus primarily on input from group members. They discuss their experiences of the past week, including difficulties encountered, and offer mutual encouragement and support. Sessions are client (not therapist) oriented, as they emphasize mutual support rather than didactic input from the therapist. The therapist facilitates client interaction and mutual support outside formal sessions. During sessions there can be several conversations at the same time and, with this approach, groups can accommodate 20-25 participants and tend to work better with such numbers.

The method used to increase group interaction was the BIE exercise. This is a method used to increase social support amongst group members. An evaluation of the effectiveness of this method was requested after its incorporation. BIE is an exercise in which group members are asked to get into groups of two and share their reasons for attending smoking cessation group support and their experiences of quitting smoking. They are also told that they will take it in turns to introduce the other person to the rest of the group and to explain their reasons for trying to quit smoking. The main reason for its incorporation and retrospective evaluation is that it was believed that this method would be effective. The rationale behind this method is that it can increase social support at an early stage by raising awareness of the fact that group members share a common goal. Group interventions can offer smokers a support network in which individuals can become members of a group of people who share the same interests and activities (Sarafino, 2002).

It was hypothesized that smokers who attend sessions where the BIE exercise is incorporated are more likely to quit smoking and to remain abstinent for the duration of the 
treatment when compared to smokers who attend a traditional HGI (control group).

\section{Results}

\subsection{Attendance}

A total of 51 (73\%) of the participants in the control group attended the sessions and $19(27 \%)$ dropped out. A total of 55 $(79 \%)$ of the participants from the treatment group attended the sessions and 15 (21\%) dropped out. Socio demographic information was collected regarding participants' educational status and ethnic background (Tables $1 \& 2$ )

Table 1. Educational status of participants.

\begin{tabular}{cccccc}
\hline Education & $\begin{array}{c}\text { No } \\
\text { education }\end{array}$ & GCSE & A-levels & Degree & Other \\
\hline HGI & 48 & 17 & 13 & 9 & 13 \\
HGI + & 46 & 20 & 10 & 9 & 15 \\
BIE & 46 & & \\
\hline
\end{tabular}

Table 2. Ethnic background of participants.

\begin{tabular}{ccccc}
\hline Background & $\begin{array}{c}\text { White } \\
\text { British } \\
(\%)\end{array}$ & $\begin{array}{c}\text { Irish } \\
(\%)\end{array}$ & $\begin{array}{c}\text { Indian } \\
(\%)\end{array}$ & $\begin{array}{c}\text { Other } \\
(\%)^{*}\end{array}$ \\
\hline HGI & 85 & 5 & 4 & 6 \\
HGI + BIE & 89 & 3 & 3 & 5 \\
\hline
\end{tabular}

*(Other includes: White, White and Black, Caribbean, White/Black African, White and Asian, any other mix, Pakistani, Bangladeshi, Any other Asian origin, Caribbean, African, any other ethnic background and ethnic background not stated)

There were no significant mean differences in attendance between the control group and the treatment group, even though there was a higher rate of attendance in the second group [ $\mathrm{t}(69)=0.782, \mathrm{p}>.005]$.

\subsection{Outcome}

In the control group, 33 participants $(47 \%)$ successfully quit smoking for four weeks and 37 (53\%) failed to do so.

In the group in which the BIE had been incorporated into treatment, $(66 \%)$ successfully quit smoking for four weeks and 24 (34\%) failed to do so.

Smokers who joined the clinic between January 2004 and April 2004 when the rapport-building intervention was incorporated into the treatment were more likely to remain abstinent for four weeks $[\mathrm{t}(69)=0.2195, \mathrm{p}<.001]$.

The findings indicate that the groups with an emphasis on social support and where rapport was built up from the start were significantly more successful.

\section{Discussion}

The findings of this study provide some evidence for the effectiveness of social support strategies in a smoking cessation group context.

The Hajek method (1989) suggests that a good rapport, social support and commitment are the main goals of group therapy. This study suggests that group methods, rapport and social support play a role in group dynamics which affect therapeutic outcomes. Incorporating a simple intervention whereby patients address each other's motives for joining the clinic and introduce their peers augments cohesiveness. It is likely that the perception of other group members in a similar stage of change improves the probability of being able to abstain from smoking.

The most interesting fact about this study is that it sheds light on the fact that it is possible to make a difference without incurring any further costs to the National Health Service.

\subsection{Limitations}

One of the limitations of this study is that it was conducted on a small scale, looking at short-term abstinence. Therefore, there are some potential threats to the external validity of the study, as the findings might not be generalizable to larger populations and there is little evidence to show that they are consistent across time. Furthermore, the individuals taking part in the study were not followed up after a year in order to cross-validate these findings.

\section{Conclusions}

As this study indicates, social interaction plays a role in outcomes, and as such it is important that smoking cessation interventions are revised with a view to addressing group processes. Despite the fact that smoking has previously been a highly social behavior, this trend is changing. As smokers interact with other smokers in the same stage of change (Prochaska \& DiClementi, 1993), their cognitions about smoking are likely to change. They might see in each other positive role models, thus reinforcing their motivation to change. The impact of positive social interaction should not be underestimated, but understandably it is hard to change the cognitions of adults who have spent most of their lives associating smoking with social desirability.

This study also provides some evidence for more tailored approaches. The BIE can be easily incorporated into any group smoking cessation intervention. However, it is also important to explore whether or not smokers are more likely to remain abstinent over a longer period of time if they are provided with consistent and continuous social support during the maintenance stage. More research is needed to evaluate the impact of continuous social support interventions post-cessation in maintaining abstinence from smoking.

\section{REFERENCES}

[1] Coppotelli, H. C., \& Orleans, C. T. (1985). Partner support and other determinants of smoking cessation maintenance 
among women. Journal of Counseling and Clinical Psychology, 53(4), 445-460.

[2] Cinciripini, P. M., Cinciripini, L. G., Wallfisch, A., Haque, W., \& Van Vunakis, H. (1996). Behavior therapy and the transdermal nicotine patch: Effects on cessation outcome, effect and coping. Journal of Consulting \& Clinical Psychology, 64(2), 314-323.

[3] Diguisto, E., \& Brick, K. D. (1995). Matching smokers to treatment: Self-control versus social support. Journal of Consulting and Clinical Psychology, 63(2), 290-295.

[4] Department of Health. (1998a). Smoking kills: A white paper on tobacco [White Paper].

[5] Department of Health. (1998b). Statistics on smoking: England, 1976 to 1996 [Statistics Bulletin].

[6] Department of Health. (1998a). Smoking kills. London: Department of Health.

[7] Department of Health. (2004). Smoking-related behavior and attitudes. ONS Omnibus Survey.

[8] Earles J., Folen R. A., M., Kellar, M., Geralde, R., \& Dydek, C. (2002). Clinical effectiveness of sustained-released bupropion and behavior therapy for tobacco dependence in a clinical setting. Military Medicine, 167(11), 923-925.

[9] Erens B., Primatesta P., Prior G., \& Madhavi B. (2001). Health survey for England: The health of the minorities ethnic groups '99. London: Stationary Office.

[10] Feeney, G. F., McPherson, A., Connnor, J. P., McLister, A., Young, R. M., \& Garrahy, P. (2001). Randomized controlled trial of two cigarette quit programmes in coronary care patients after acute myocardial infarction. Internal Medicine Journal, 31, 470-475.

[11] Fisher, E. B. (1997). Two approaches to social support in smoking cessation: Commodity model and nondirective support. Addictive Behaviors, 22(6), 819-833.

[12] Graham, H., \& Derr, G. (1999). Patterns and predictors of smoking cessation among British women. Health Promotion International, 14, 231-239.

[13] Hajek, P. (1986). Nicotine chewing gum in group treatment of smokers. In: J. K. Ockene (Ed.), Pharmacological treatment of tobacco dependence: Proceedings of the World Congress, Nov 4-5, 1985 (pp. 226-233). Harvard University, Cambridge: Institute for the Study of Smoking Behavior and Policy.

[14] Hajek, P. (1989). Withdrawal-oriented therapy for smokers. British Journal of Addiction, 84, 591-598.

[15] Hajek, P. (1996). Current issues in behavioral and pharmacological approaches to smoking cessation. Journal of Addictive Behavior, 21(6), 699-707.

[16] Hajek, P., Taylor, T. Z. \& Mills, P. . (2002). Brief intervention to help patients to give up smoking after myocardial infarction and bypass surgery: Randomised controlled trial. British Medical Journal, 324(7329), 485-494.

[17] Hajek, P., West, R., Lee, A., Foulds, J., Owen, L., Eiser, J., Main, R. N. (2001). Randomized controlled trial of a midwife-delivered brief smoking cessation intervention in pregnancy. Journal of Addiction, 96(3), 85-494.
[18] Kviz, F. J., Crittenden, K. S., Clark, M. A., \& Madura, K. J. (1994). Buddy support among older smokers in a smoking cessation program. Journal of Aging \& Health, 6(2), 229-254.

[19] Kviz, F. J., Crittenden, K. S., Madura, K. J., \& Warnecke, R. B. (1994). Use and effectiveness of buddy support in a self-help smoking cessation program. American Journal of Health Promotion, 8(3), 191-201.

[20] Marks, D. F., \& Sykes, C. M. (2002). Randomised controlled trial of cognitive behavioural therapy for smokers living in a deprived area of London: Outcome at one-year follow-up. Psychology, Health and Medicine, 7, 17-24.

[21] Marks, D. F., \& Sykes, C. M. (2001). Effectiveness of a cognitive behaviour therapy self-help programme for smokers in London, UK. Health Promotion International, 16, 255-260.

[22] May, S., \& West, R. (2000). Do social support interventions ("buddy systems") aid smoking cessation? A review. Patient Education Counseling, 9(4), 15-422.

[23] May, S., West, R. P., McEwen, A., \& McRobbie, H. (2006). Randomized controlled trial of a social support ("buddy") intervention for smoking cessation. Patient Education Counseling, 64(1-3), 235-41.

[24] Mermelstein, R., Cohen, S., Lichtenstein, E., Baer, J. S., \& Kamarck, T. (1986). Social support and smoking cessation and maintenance. Journal of Consulting and Clinical Psychology, 54, 447-453.

[25] Mermelstein, R., Cohen, S., Lichtenstein, E., Baer, J. S., \& Kamarck. T. (1986). Social support and smoking cessation and maintenance. Journal of Consulting and Clinical Psychology, 54, 447-453.

[26] Murray, R. P., Johnston, J. J., Dolce, J. J., Wong Lee, W., \& Harra, P. (1995) Social support for smoking cessation and abstinence: The lung health study. Addictive Behaviors, 20(2), 159-170.

[27] National Health Service (NHS) Information Centre. (2010). Statistics on NHS stop smoking services: England. April 2009-March 2010.

[28] National Institute for Health and Clinical Excellence (NICE). (2002). Guidance on the use of nicotine replacement therapy (NRT) and bupropion for smoking cessation. London: NICE.

[29] NICE. (2008). Smoking cessation services in primary care, pharmacies, local authorities and workplaces, particularly for manual working groups, pregnant women and hard to reach communities. London: NICE.

[30] Ockene, J., Kristellar, J., Ockene, I., \& Goldberg, R. (1992). Smoking cessation and severity of illness. Health Psychology, 11, 119-126.

[31] Odgen, J. (2001). Health psychology. In: J. Naidoo \& J. Wills (Eds.), Health studies, an introduction (pp. 69-100). Chippenham, Wiltshire, UK: Palgrave.

[32] Orleans, C. T., Arkin, E. T., Backinger, C., Best, A., Crossett, L., Grossman, (...)\& Thornton, A. H. (2003). The youth tobacco cessation collaborative and national blueprint for action: Coordinating efforts to improve tobacco cessation among adolescents and young adults. American Journal of Health Behavior, 27(2), S103-S119. 
[33] Pagel, M., \& Davidson, A. R. (1984). A comparison of three attitudinal models for the prediction of contraceptive behavior. Journal of Personality and Social Psychology, 7, 517-533.

[34] Pirie, P. L., Rooney, B. L., Pechacek, T. F., Lando, H. A., \& Schmid, L. A. (1997). Incorporating social support into a community-wide smoking-cessation contest. Addictive Behaviors, 27(1), 131-137.

[35] Prockaska, J. O., DiClementi, C. C., \& Norcross, J. C. (1992). In search of how people change: Applications to addictive behaviors. American Psychologist, 47, 1102-1114.

[36] Prockaska, J. O., DiClementi, C. C., Veucer, W. F., \& Rossi, J. S. (1993). Standardized, individualized, interactive, and personalized self-help programs for smoking cessation. Health Psychology, 13, 39-46.

[37] Prochaska , J. O., \& DiClemente, C. C. (1983). Stages and processes of self change in smoking. Journal of Consulting and Clinical Psychology, 51, 390-395.

[38] Raw, M., McNeill, A., \& West, R. (1998) Smoking cessation guidelines for health professionals. A guide to effective smoking cessation interventions for the health care system. Thorax, 53(5), 1-17.

[39] Razavi, D., Vandecasteele, H., Primo, C., Bodo, M., Debrier, F., Verbist, H., Pethica, D., Eerdekens, M., \& Kaufman L. (1999). Maintaining abstinence from cigarette smoking: Effectiveness of group counseling and factors predicting outcomes. European Journal of Cancer, 35(8), 1238-47.

[40] Sarafino, E. P. (2002). Health psychology, biopsychological interaction. 3rd ed. New York: Wiley.

[41] Simon A. J., Solkowitz, N., S., Carmody, T. P., \& Browner, W. S. (1997). Smoking cessation after surgery. Archives of
Internal Medicine, 157, 1371-6.

[42] Stead, L. F., \& Lancaster, T. (1998) Group behavior therapy programs for smoking cessation (Cochrane Review). The Cochrane Library, Issue 3, Update Software, Oxford.

[43] Stead, L. F., \& Lancaster, T. (2002). Group behavior therapy programs for smoking cessation (Cochrane Review). The Cochrane Library, 3, Update Software, Oxford.

[44] Steimle, S. (1999). New EU report: More women are smoking. Journal of the National Cancer Institute, 3, 212-213.

[45] [Tang, M, \&Law, N. W. (1995). An analysis of the effectiveness of interventions intended to help people stop smoking. Thorax, 53(5), S1-S18.

[46] Taylor, C. B., Miller, N. H., Herman, S., Smith, P. M., Sobel, D., Fisher, L., \& DeBusk, R. F. (1996). A nurse-managed smoking cessation program for hospitalized smokers. American Journal of Public Health, 86(11), 1557-1560.

[47] Viswesvaran, C., \& Schmidt, F. L. (1992). A meta-analytic comparison of the effectiveness of smoking cessation methods. Journal of Applied Psychology, 77(4), 554-61.

[48] West, R., Edwards, M., \& Hajek, P. (1998). A randomized controlled trial of a 'buddy' system to improve success at giving up smoking in general practice. Addiction, 93(7), 1007-1011.

[49] Pires-Yfantouda, R. (2010). Smoking cessation interventions: Is "one size fits all" all there is?: A critique of standardised approaches to smoking cessation [published thesis]. VDM Verlag Dr. Müller. London: UK. 